This item was submitted to Loughborough's Research Repository by the author.

Items in Figshare are protected by copyright, with all rights reserved, unless otherwise indicated.

\title{
A finite element analysis of bending stresses induced in external and internal involute spur gears
}

PLEASE CITE THE PUBLISHED VERSION

PUBLISHER

(C) IMechE / Professional Engineering Publishing

LICENCE

CC BY-NC-ND 4.0

REPOSITORY RECORD

Andrews, J.D.. 2008. "A Finite Element Analysis of Bending Stresses Induced in External and Internal Involute Spur Gears”. figshare. https://hdl.handle.net/2134/3946. 
This item was submitted to Loughborough's Institutional Repository (https://dspace.lboro.ac.uk/) by the author and is made available under the following Creative Commons Licence conditions.

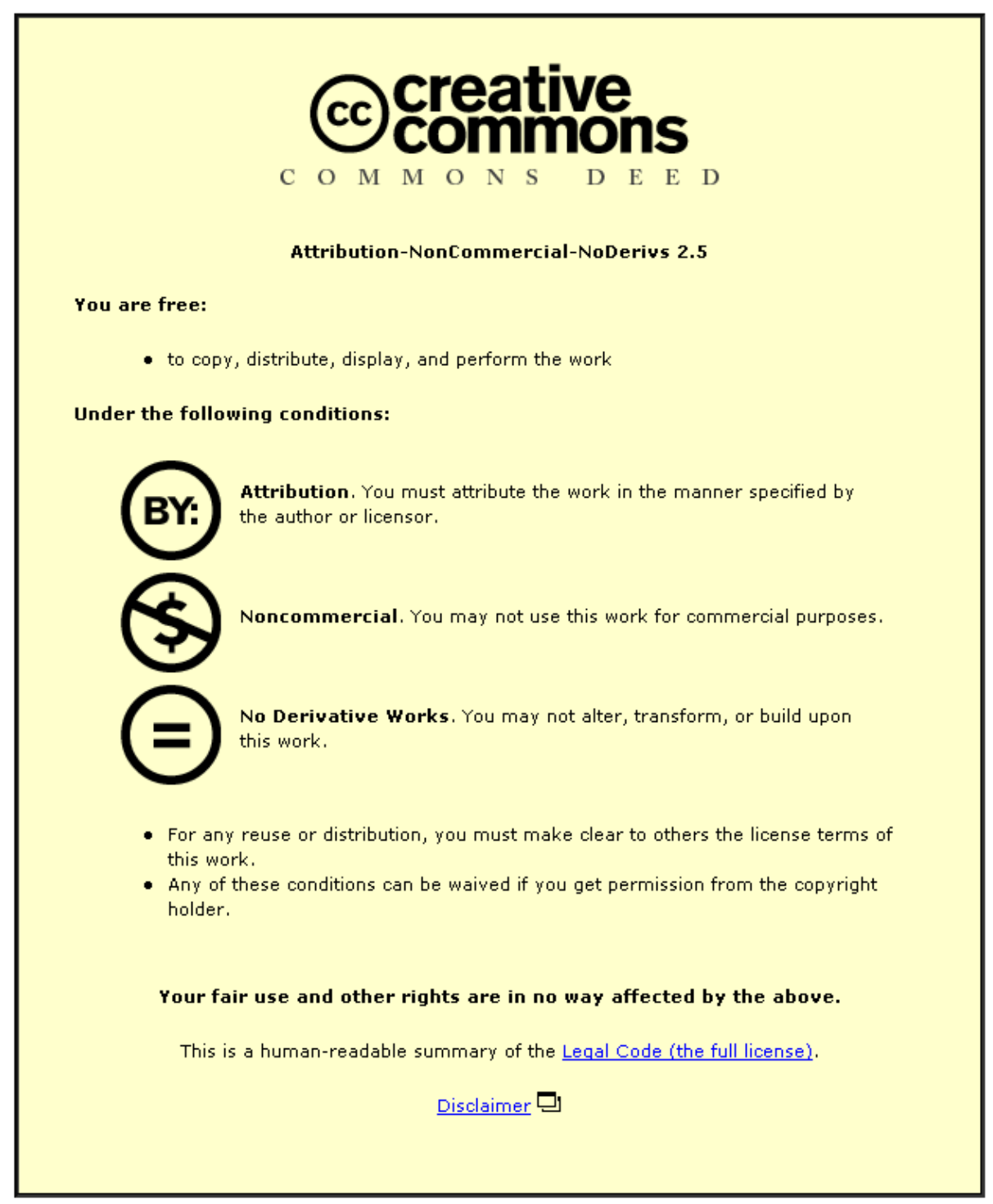

For the full text of this licence, please go to: http://creativecommons.org/licenses/by-nc-nd/2.5/ 


\title{
A FINITE ELEMENT ANALYSIS OF BENDING STRESSES INDUCED IN EXTERNAL AND INTERNAL INVOLUTE SPUR GEARS
}

\section{J. D. ANDREWS Department of Mathematical Sciences, Loughborough University of Technology, UK}

\begin{abstract}
This paper describes the use of the finite element method for predicting the fillet stress distribution experienced by loaded spur gears. The location of the finite element model boundary and the element mesh density are investigated. Fillet stresses predicted by the finite element model are compared with the results of photoelastic experiments. Both external and internal spur gear tooth forms are considered.
\end{abstract}

\section{INTRODUCTION}

Advances in engineering technology in recent years have brought demands for gear teeth which can operate at ever-increasing load capacities and speeds. When failures occur they are expensive, not only in terms of the cost of replacement or repair, but also the costs associated with the down-time of the system of which they are part. Reliability is thus a critical economic factor and for designers to produce gears with a high reliability they need to be able to accurately predict the stresses experienced by the loaded gear teeth.

For modern, high speed, high load gearing the results obtained with conventional gear strength equations are inaccurate. In 1893 Lewis (1) $\dagger$ developed and presented a publication containing the well-known 'Lewis formula'. By considering the gear tooth as a cantilever beam Lewis produced a method which gives both the magnitude of the maximum bending stress and the location of the 'weakest section'. More recent workers have identified many deficiencies in the Lewis approach (2) (3) and developed more sophisticated formulae many of which retained the classical Lewis construction with minor modifications such as Dolan and Broghamer (4) and Kelley and Pedersen (5). These early attempts to produce a formula which relates the maximum fillet bending stress to the design parameters are based on a small number of experiments using photoelastic models.

In more recent work finite element predictions have replaced the photoelastic experiments as a means of investigating the effect that design parameter changes have upon the bending stress (6) (8). As with the photoelastic works, most of the formulae derived are based on a relatively small number of analyses to investigate the effect of all the design parameters.

There is also the additional criticism of these semiempirical formulae that they are derived from either photoelastic work of which the majority was carried out using suspect model materials, or finite element work of which the earlier models featured rigidly constrained

\footnotetext{
The MS. of this paper was received at the Institution on 18 May 1990 and accepted for publication on 5 February 1901
}

+ References are given in the Appendix. boundaries which were located in the fillets under investigation.

Whilst numerous attempts have been made to produce acceptable and at times complex formulae, these have not always been associated with increased understanding of fundamental gear deflection behaviour.

It would be advantageous to be able to analyse every proposed gear design to establish the maximum fillet bending stress. With finite element packages and powerful digital computers becoming increasingly available in industry there is no reason why this should not be the case. If the finite element method can be shown to accurately model gear tooth behaviour then this course of action would be preferable to the use of the suspect semiempirical formulae as advocated by the majority of the standards.

This paper investigates the stresses predicted in spur gear teeth of both external and internal form and suggests the form of the finite element model from which accurate results can be obtained. Direct comparisons have been made with the photoelastic experiments on spur gear teeth carried out the Allison and Hearn (9).

\section{FINITE ELEMENT MODEL DEFINITION}

In order to model the gear using the finite element method, the first step required was to establish the domain over which the results were to be calculated. In most applications this domain of interest is obtained intuitively from the physical geometry of the structure. For gear teeth, however, the boundaries for this domain were not immediately apparent. The area of interest could be approximated by a single gear tooth or be extended to include the whole gear. To evaluate the stress distribution in the fillet of a loaded tooth model boundaries must be established which would accurately represent the tooth behaviour. Since it was thought to be inefficient to model the complete gear wheel, the problem was to decide where to locate the boundary between the region for analysis and the remainder of the gear along which zero displacement can be assumed.

In order to ascertain a model boundary, finite element runs were executed using the model shown in Fig. 1. This 


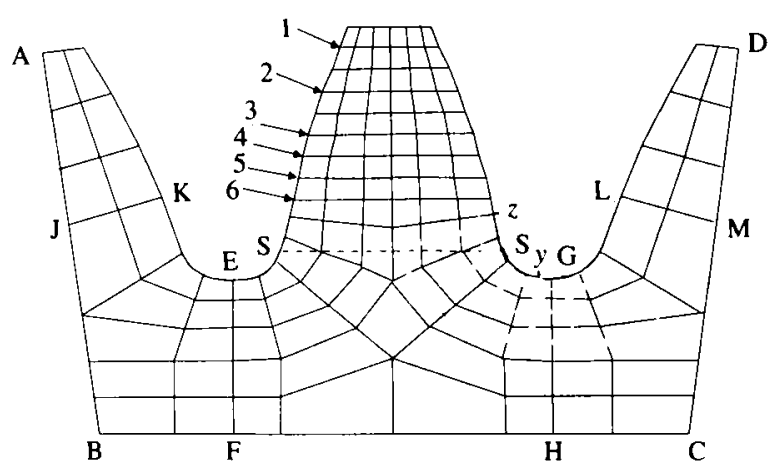

Fig. 1. Finite element mesh used for gear tooth analysis

model was constructed using 8-noded parabolic isoparametric elements. Incorporated into the region of interest was not only the loaded tooth but also half of the two adjacent teeth. One hundred and twenty three elements were used for the discretisation, giving a mathematical model which consisted of 880 degrees of freedom. The gear booth characteristics and materials properties are:

$\begin{array}{lc}\text { module }\left(m_{\mathrm{t}}\right) & 5 \mathrm{~mm} \\ \text { pressure angle } & 20 \text { degrees } \\ \text { number of teeth } & 45 \\ \text { addendum } & 1.0 \mathrm{~m}_{\mathrm{t}} \\ \text { dedendum } & 1.25 \mathrm{~m}_{\mathrm{t}} \\ \text { addendum modification } & 0.0 m_{\mathrm{t}} \\ \text { tip radius of cutter } & 0 \mathrm{~m}_{\mathrm{t}}\end{array}$

Young's modulus $210000 \mathrm{~N} / \mathrm{mm}^{2}$, Poissons ratio 0.3, and load $400 \mathrm{~N} / \mathrm{mm}$ width.

Mesh boundary ABCD of the tooth was fixed rigidly. A total of six analyses were made for differing tooth contact conditions. A constant load was applied, normally to the profile, for contact points located at $0.2 m_{t}$, $0.6 m_{t}, 1.0 m_{t}, 1.2 m_{t}, 1.4 m_{t}$, and $1.6 m_{t}$ from the tooth tip. Marked load positions 1-6, respectively, in Fig. 1.

It was then necessary to investigate whether this model, which considered half of each tooth adjacent to that of interest, had boundaries sufficiently remote from the fillet to justify the rigid constraints applied along the boundaries. This was carried out using a new, extended model which comprised three full teeth and two half teeth.

The analyses were repeated, and again investigations were made into the displacements occurring at positions equivalent to boundary ABCD in Fig. 1. The displacement figures obtained at these locations were very small in magnitude, indicating that a rigidly fixed boundary at this point would not introduce significant errors. As a final check, maximum fillet stresses produced by the models were compared. Results differed by less that 1 percent with the mesh shown in Fig. 1 producing the higher stresses. This was consistent with the assumption that the closer boundary location would provide a stiffening effect for the tooth. As the model illustrated in Fig. 1 produced pessimistic stress predictions which had an error of less that 1 percent it was considered that the additional computer effort involved in analysing gear teeth using the larger mesh was not justified for the small increase in accuracy achieved. The conclusion was, therefore, that considering half a tooth either side of that to which the load was applied gives a boundary sufficiently remote from the fillets to obtain acceptably accurate results.

Further investigations were made using the finite element mesh on which the two half teeth adjacent to the loaded tooth were truncated at lines JK and LM in Fig. 1. The results showed that this truncation gave no loss of accuracy.

Having established a solution domain, it remained to estabish the density of elements needed. Although an increase in the number of elements generally means more accurate results, there will be a certain point where the accuracy cannot be improved by any significant amount. It is this point which needs to be established since the use of an excessive number of elements involves unnecessary computer effort. To investigate the need to reduce the element size further than that shown in Fig. 1 to obtain increased accuracy, a mesh was constructed to represent the fillet region only. The tooth fillet was represented by four times the density of elements used in the complete tooth. Figure 2 shows the principal stresses in the tooth fillets between points $Y$ and $Z$ marked on Fig. 1 for load positions 1,3 , and 6 . Those evaluated from the coarse tooth model (c1, c3, c6) and those calculated by the refined fillet model $(\mathrm{f} 1, \mathrm{~B}, \mathrm{f} 6)$ can be compared. No significant increase in the accuracy of the stresses is apparent. It is, therefore, concluded that the degree of element refinement represented by the mesh in Fig. 1 is sufficient to model the gear tooth accurately.

\section{AUTOMATIC MESH GENERATION}

Constructing the model geometry, subdividing into elements and then preparing the input data for a finite element program is, for complex shapes such as a gear tooth, a difficult and time consuming task. To quicken this task, and also avoid the errors associated with manual data preparation, an automatic process has been devised and implemented on a computer.

The computer program takes the parameters which define the geometry of an external spur gear tooth together with data which determines the mesh resolution and creates a data file of nodal coordinates and element topologies in the format required by the analysis program.

Eight parameters are required to define an external tooth form. Some of these parameters relate directly to the gear itself whilst others are given in terms of the rack used in its generation. The eight variables are:

(1) pressure angle of the generating rack $\left(\alpha_{t}\right)$;

(2) addendum factor (height of tooth flank above median line) $\left(a_{\mathrm{og}}\right)$

(3) dedendum factor (height of rack above median) $\left(h_{\mathrm{ot}}\right)$;

(4) rack module $\left(m_{t}\right)$;

(5) number of teeth on gear $(Z)$;

(6) rack tip radius factor $\left(r_{o t}\right)$;

(7) modification factor $\left(s_{0}\right)$;

(8) thickness ( $t$ ). 

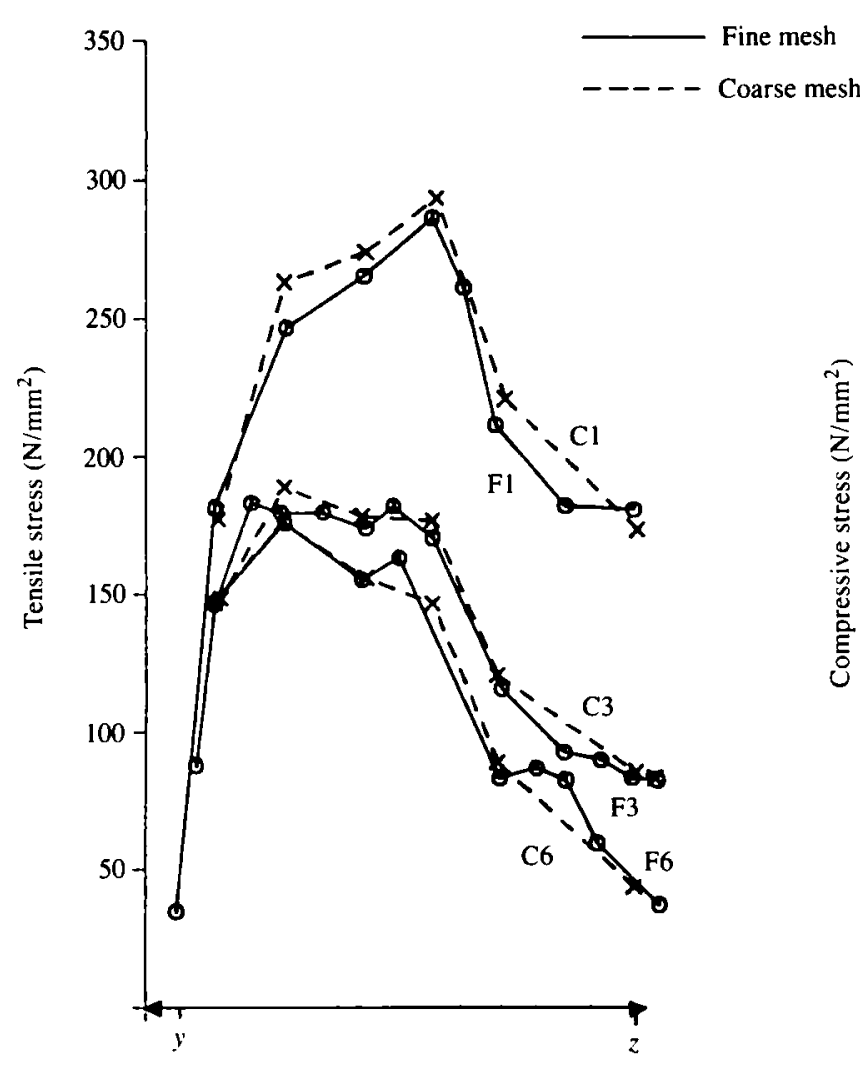

Position in fillet

Fig. 2. Comparison of fillet stresses for fillet mesh and complete tooth mesh

The parameters above which are factors, are obtained by dividing by the module to give dimensionless quantities.

\subsection{The geometry of external involute spur gears}

One of the most important properties of involute spur gear teeth is that is that they can be generated by a rack whose teeth have straight edges. Manufacture of external spur gear teeth can be accomplished by a process which moves the rack in a straight line in the plane of the gear blank whilst the blank is rotated. During the generation process there will be some radius on the gear blank at which the tangential velocities of both the gear and the rack will be equal. This is termed the rolling radius and it is this which determines the number of teeth generated and must be carefully controlled by the manufacturing machine. For non-modified generating processes the rack is adjusted so that the space between the two teeth at the rolling line is equal to half the circular pitch $\pi m_{1} / 2$. In modified processes the modification factor, $s_{0}$, is the non-dimensional distance between the median line and the rolling line, as shown in Fig. 3.

The gear tooth prolife can be split into three distinct regions, each generated by a different part of the rack. The first part of the gear profile, the involute edge, is cut by the linear flank of the rack. It is the tip of the rack which cuts the second section, the root circle. The final portion, the fillet, is the sect on of the profile which joins the involute flank to the root circle. Generation of this curve is performed by the rack tip radius.

Erik Wennerstrom (10) derived expressions for the involute flank and fillet curves in terms of an angular coordinate $\phi$, the rolling angle, relative to a fixed angle $\phi_{1}$.

The equations express the locus of the flank and fillet curves in the dimensionless coordinate system $\xi, \eta$ which are fixed to the gear blank and have their origin at the gear wheel centre (Fig. 4). The coordinates are divided by the rack module to obtain the non-dimensional system.

The non-dimensional coordinates $\left(\xi_{i}, \eta_{i}\right)$ of the involute gear flank expressed in terms of parameter $\phi$ are

$$
\begin{aligned}
\xi_{\mathrm{i}}= & \frac{Z}{2} \sin \left(\phi_{1}+\phi\right) \\
& -\left[\left(h_{0 \mathrm{t}}-s_{0}+r_{0 \mathrm{t}} \frac{1-\sin \alpha_{\mathrm{t}}}{\sin \alpha_{\mathrm{t}}}\right) \tan \alpha_{\mathrm{t}}+\frac{Z}{2} \phi\right] \\
& \times \cos \alpha_{\mathrm{t}} \cos \left(\phi_{1}+\phi-\alpha_{\mathrm{t}}\right) \\
\eta_{\mathrm{i}}= & \frac{Z}{2} \cos \left(\phi_{1}+\phi\right) \\
& +\left[\left(h_{0 \mathrm{t}}-s_{0}+r_{0 \mathrm{t}} \frac{1-\sin \alpha_{\mathrm{t}}}{\sin \alpha_{\mathrm{t}}}\right) \tan \alpha_{\mathrm{t}}+\frac{Z}{2} \phi\right] \\
& \times \cos \alpha_{\mathrm{t}} \sin \left(\phi_{1}+\phi-\alpha_{\mathrm{t}}\right)
\end{aligned}
$$




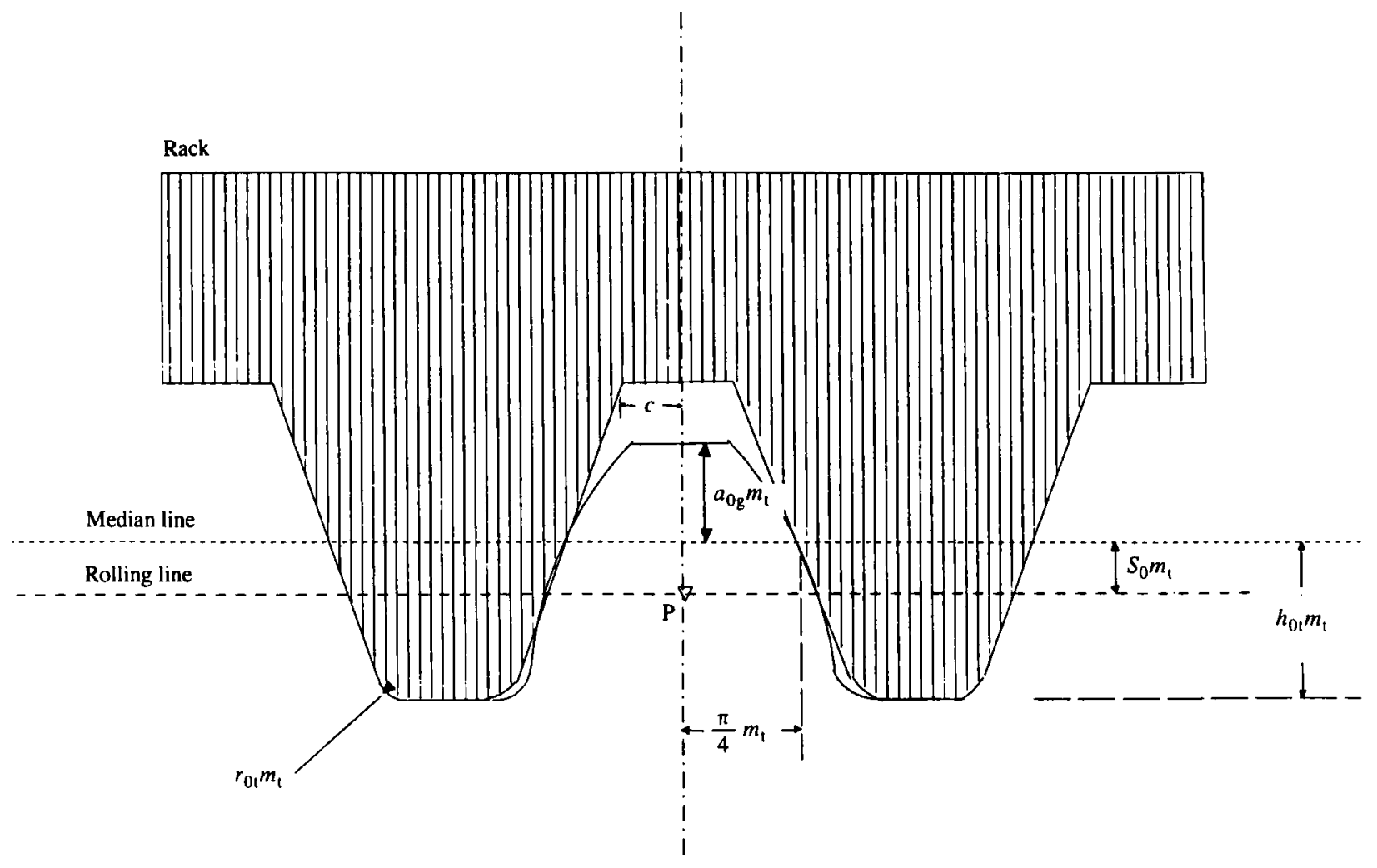

Fig. 3. Gear tooth parameter definitions

where

$$
\phi_{1}=\frac{2}{Z}\left(\frac{\pi}{4}+h_{0 t} \tan \alpha_{t}+r_{0 t} \frac{1-\sin \alpha_{t}}{\cos \alpha_{t}}\right)
$$

The fixed angle $\phi_{1}$ is illustrated in Fig. 4 and is the polar angle from the $\eta$ axis to the position marked $F$. This corresponds to the position where the rack has gen-

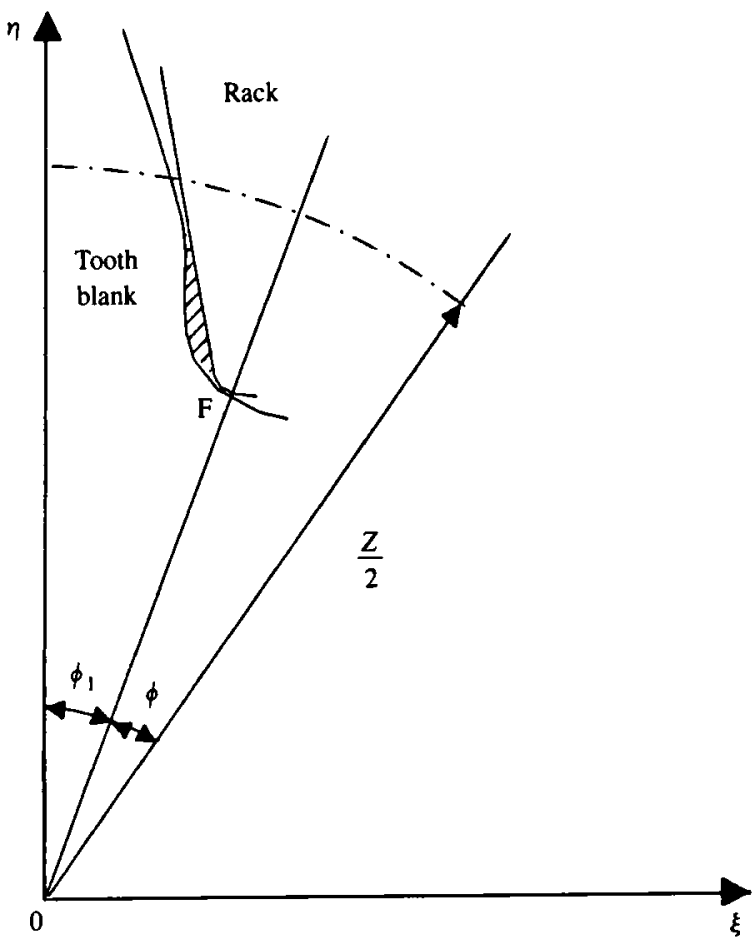

Fig. 4. Local non-dimensional coordinate system erated the last point of the root circle, i.e., the initial point of the fillet profile.

For the fillet curve the profile equations are given by

$$
\begin{gathered}
\xi_{\mathrm{f}}=\left(\frac{Z}{2}-h_{0 \mathrm{t}}+r_{0 \mathrm{t}}+s_{0}\right) \sin \left(\phi_{1}+\phi\right) \\
-\frac{Z}{2} \phi \cos \left(\phi_{1}+\phi\right)
\end{gathered}
$$$$
-r_{0 t}\left[\frac{\frac{Z}{2} \phi \cos \left(\phi_{1}+\phi\right)+\left(h_{0 t}-r_{0 t}-s_{0}\right) \sin \left(\phi_{1}+\phi\right)}{\sqrt{\left\{\left(\frac{Z}{2} \phi\right)^{2}+\left(h_{0 t}-r_{0 t}-s_{0}\right)^{2}\right\}}}\right]
$$

$$
\eta_{\mathrm{f}}=\left(\frac{Z}{2}-h_{0 \mathrm{t}}+r_{0 \mathrm{t}}+s_{0}\right) \cos \left(\phi_{1}+\phi\right)
$$

$$
+\frac{Z}{2} \phi \sin \left(\phi_{1}+\phi\right)
$$

$+r_{0 \mathrm{t}}\left[\frac{\frac{Z}{2} \phi \sin \left(\phi_{1}+\phi\right)+\left(h_{0 \mathrm{t}}-r_{0 \mathrm{t}}-s_{0}\right) \cos \left(\phi_{1}+\phi\right)}{\sqrt{\left\{\left(\frac{Z}{2} \phi\right)^{2}+\left(h_{0 \mathrm{t}}-r_{0 \mathrm{t}}-s_{0}\right)^{2}\right\}}}\right]$

this equation is applicable providing

$$
s_{0}<h_{0 t}-r_{0 t}
$$

JOURNAL OF STRAIN ANALYSIS VOL 26 NO 31991 (C) IMechE 1991 
Intersection between flank and fillet profiles occurs at a point where the radius is obtained using Buckingham's (11) equation

$$
R_{\mathrm{f}}=\sqrt{ }\left[\left\{R \sin \phi_{\mathrm{R}}-\left(b_{\mathrm{a}} / \sin \phi_{\mathrm{R}}\right)\right\}^{2}+R_{\mathrm{b}}^{2}\right]
$$

where $R_{\mathrm{f}}$ is the fillet/flank intersection radius, $R$ is the pitch radius of gear, $\phi_{\mathrm{R}}$ is the pressure angle at $R, b_{\mathrm{a}}$ is the distance from the pitch line of the rack to the point of tangency of the rounded corner, and $R_{\mathrm{b}}$ is the base circle radius.

\subsection{Mesh generation procedure}

The gear tooth profile is initially mapped out within the generation program by calculating the coordinates of thirteen 'key points' located at critical positions as shown in Fig. 5. From the coordinates of these points and in some cases their associated generating angle, the complete boundary can be determined using the symmetry of a gear wheel. The first six positions illustrated in Fig. 5 are those which define the line of symmetry (1)-(3) and the model boundary (3)-(6). To obtain the coordinates of any intermediate point on these boundaries, linear interpolation can be used on the coordinates of the nearest key points located on either side. Equation (1) represents the dimensionless coordinate values of the points located on the involute flanks i.e., sections (11)-113) on the main tooth and $(7)-(8)$ for the adjacent tooth. The gear tooth fillet is mapped out by the points $8,9,10$, and 11 . For the two fillet curve portions $(8)-(9)$ and $(10)-(11)$ equation (2) applies as these are the portions of the profile generated by the rack tip radius. Finally, the root circle is located between the points 9 and 10 .

To obtain coordinates for intermediate points located on the curved portions of the tooth a knowledge of the generating angle is required for substitution into the relevant equation. For the involute portion of the profile the two angles which generate definition points 11 and 13 will be required so that the values of $\phi$ can be inter-

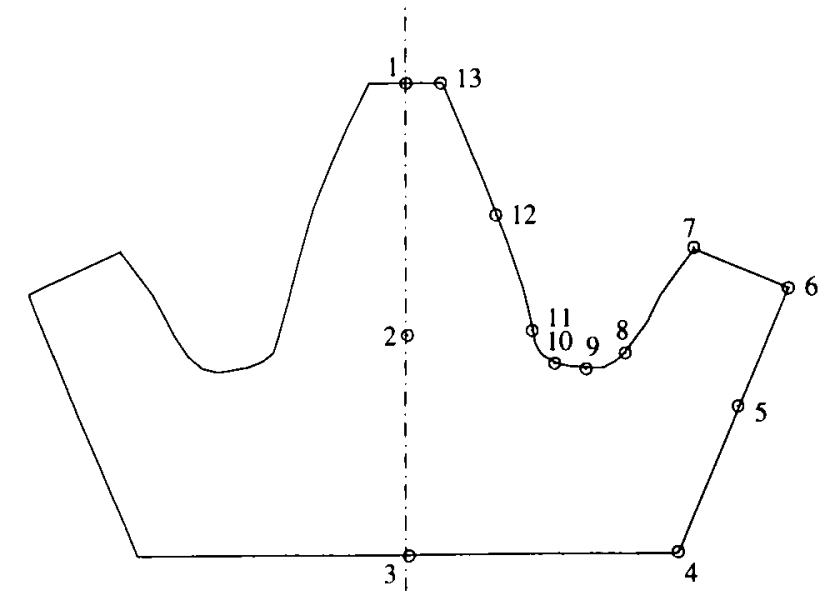

Fig. 5. Gear tooth definition points polated for any intermediate location. Point 11 corresponds to the intersection of the fillet and flank curves and will have a different generation angle for both sets of equations. The position of this point of intersection is obtained from equation (3). The generating angles for this point on the flank and fillet curves are then calculated and stored.

Mesh construction is achieved from the thirteen key points in three stages.

\section{Stage 1}

The first stage of the generation process is to establish the degree of resolution in the mesh, that is the number of elements which will be used to model different regions of the tooth. These sub-division parameters are specified in the input data. The algorithm then determines the coordinates of all the nodes located on what are termed the 'mid' and 'edge' boundaries identified by definition points $1-6$ and $7-13$, respectively.

To generate the boundary node points the tooth model is broken down into three portions; the main tooth, the root section, and the adjacent tooth. Spacing parameters define the nodal resolution within the main tooth and adjacent tooth sections. The root section boundary is then discretised considering two factors. The first is that the mesh must be formed in such a manner as to remain compatible with the meshes on the main tooth and adjacent tooth which will be of different densities. The second factor is that it must be of a sufficient density itself to model the stesses in the fillet region accurately.

\section{Stage 2}

Stage two of the mesh generation process calculates the coordinates of all the nodal points which lie within the body of the gear tooth model and assigns to each point a unique number. These internal points are located by interpolating between the corresponding nodal point coordinates which lie on the two edges bounding the right-hand side half-section. Coordinates of nodal points located on the left-hand side are evaluated using symmetry.

\section{Stage 3}

The final stage of the generation routine completes the task of producing the finite element mesh by defining the element topologies. Since the mesh was to be analysed by a finite element program which employs a frontal solution scheme, the nodal numbering sequence is irrelevant (it is only important if analysis is carried out by a 'banded solution' program). The element numbering system is optimized by minimizing the frontwidth in order to obtain an efficient solution. Mesh data are then written to an output file.

This mesh generation routine has been used in an automatic gear tooth design algorithm presented in reference (12). 


\section{EXTERNAL GEAR TOOTH BENDING STRESSES}

\subsection{Fillet surface stresses}

To examine the stress raising effects induced in the tooth fillet region for each position of load, the principal stresses have been plotted in Fig. 6. The compressive fillet stresses behave as expected, with lower stress levels being produced by the smaller bending moments associated with lower positions of load application. Stress values plotted have been obtained directly from the nodal point values and no attempt has been made to 'smooth' the curves; this enables any movement in the peak stress position to be more easily identified. It is clear that as the load point descends the flank, the location of the peak compressive stress also moves around the fillet in a direction away from the tooth tip.

In the tensile fillet located on the loaded side of the tooth, the clear relationship between load position and stress magnitude established in the compressive fillet is not repeated. The maximum principal stresses in the fillet decrease steadily as the load position descends the flank for load positions 1-4 only. As the load position nears the fillet however, the contact stress region and the bending stress region overlap bringing about "proximity effects'. When this amalgamation of stress regions occurs, the tensile components of stress from the two areas supplement each other. The effect of this can be observed for the tensile principal stresses produced for load positions 5 and 6 . Tensile stress values increase on the edge of the fillet region because of the influence of the contact stresses. This effect was also noted by Allison and Hearn (9) in their photoelastic work.

As in the compressive fillet a shift in the position of peak stress is produced and again this is in the same direction as the movement of load position.
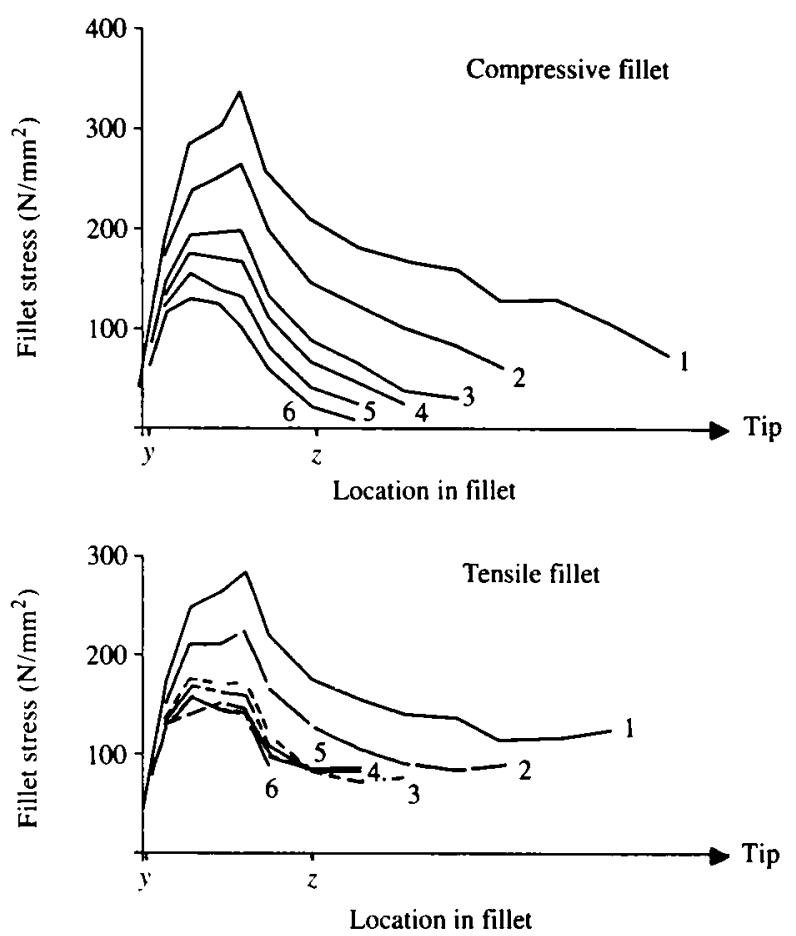

Fig. 6. Principal fillet stresses
In Fig. 7 the maximum stress values produced for each load position in both fillets have been plotted on the same graph. This more clearly illustrates the occurrence of 'proximity effects'. For high positions of load on the tooth flank, maximum compressive stress exceeds the maximum tensile stress. As the load position approaches the fillet the influence of the contact stresses reverses this trend.

\subsection{Root section stresses}

Authors in some previous works (7) (13) have assumed that the maximum fillet stresses occur at the same position in both fillets for each load case. The 'root section' is then conveniently defined as the section across the base of the tooth which joins the point of maximum tensile fillet stress to the point of maximum compressive fillet stress. If this approach were adopted for this work it would lead to a different 'root section' for each load case. The actual position of the 'root section' is not important and has been fixed as indicated $(S-S)$ in Fig. 1. This serves to illustrate trends in stresses on this section and provides a comparison between the different load cases.

For each load position 1, 3, and 6 the variation of principal stresses $\sigma_{1}, \sigma_{2}$, shear stress $\tau_{\mathrm{xy}}$, and direct stress $\sigma_{y}$ are plotted along the 'root section' resulting in graphs shown in Fig. 8. If the gear tooth were to behave as a cantilever beam, the basis of many theoretical treat-

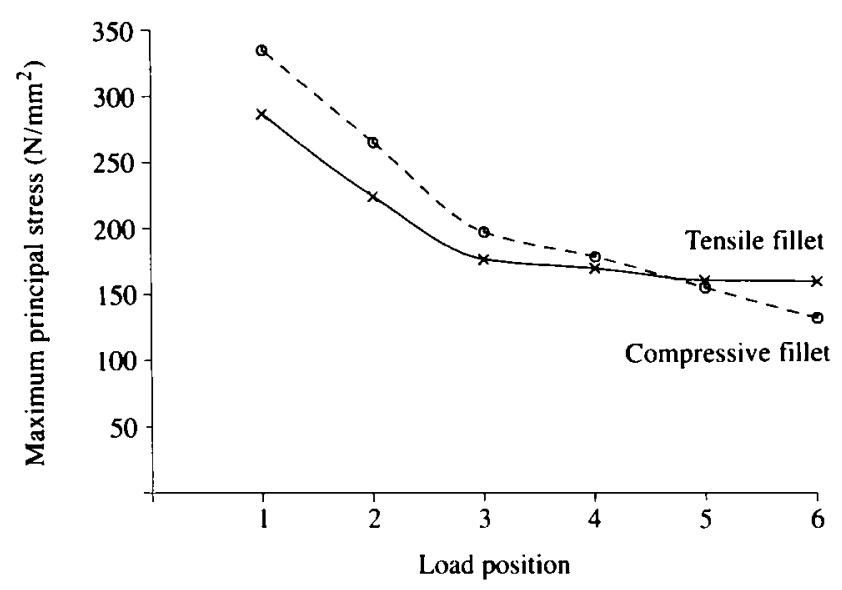

Fig. 7. Fillet stress variation with load position

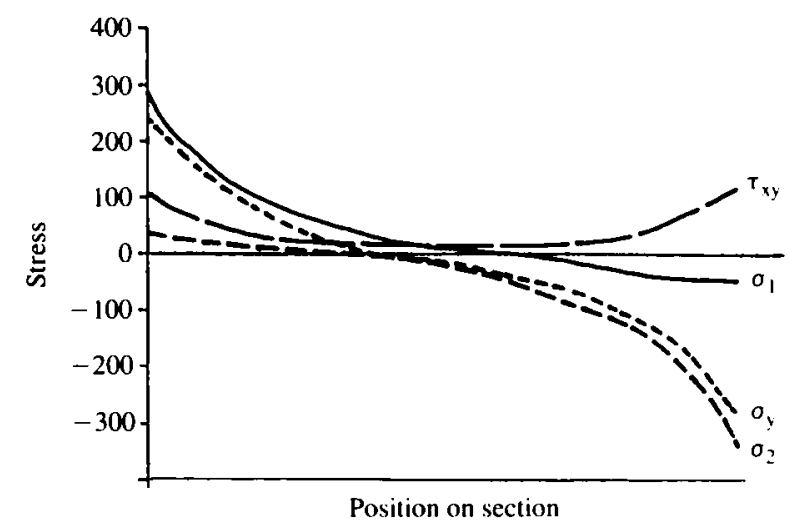

Fig. 8(a). Root section stresses for load point 1 


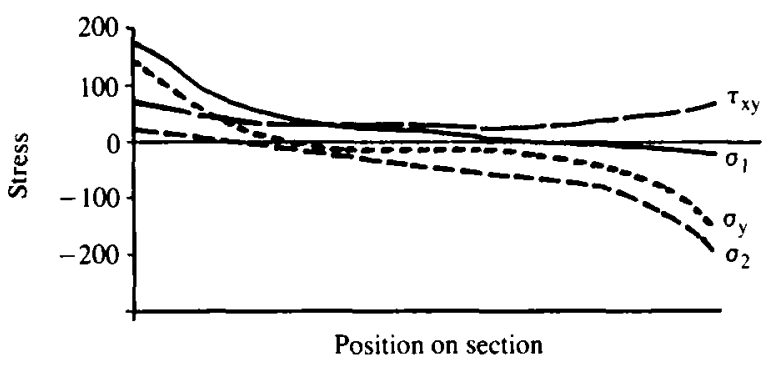

Fig. 8(b). Root section stresses for load point 3

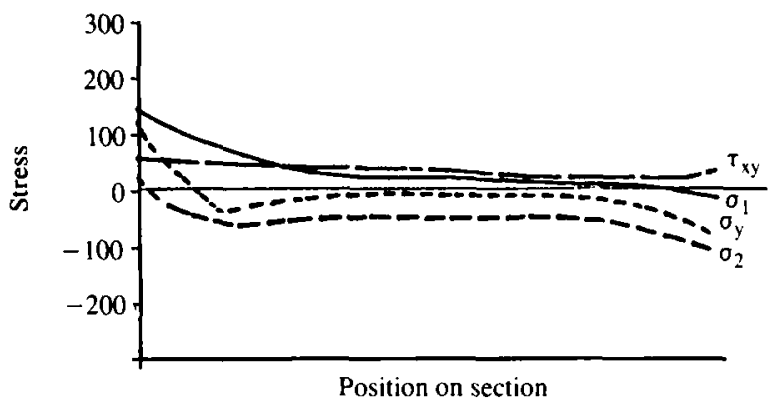

Fig. 8(c). Root section stresses for load point 6

ments, then the variation of $\sigma_{y}$ with respect to its position along the section would be linear. This is found not to be the case in practice and, future theoretical work needs to be of a far more complex nature if increased accuracy of prediction is to be obtained. Stresses plotted in this manner across the root section have similar shapes differing only in magnitude, for load positions 1 and 3 . For load position 6 the influence of the contact stress region is evident, particularly in $\sigma_{y}$.

\section{A COMPARISON OF THE RESULTS PRODUCED BY THE PHOTOELASTIC AND FINITE ELEMENT MODELS OF SPUR GEAR TEETH}

Allison and Hearn's two-dimensional photoelastic modelling of gear teeth (9) revealed features in the relationship between the fillet stresses and the load position which had not been reported by any previous worker. By direct comparison between the results obtained by Allison and Hearn and those yielded by re-modelling the same example using the finite element method the following two objectives could be achieved:

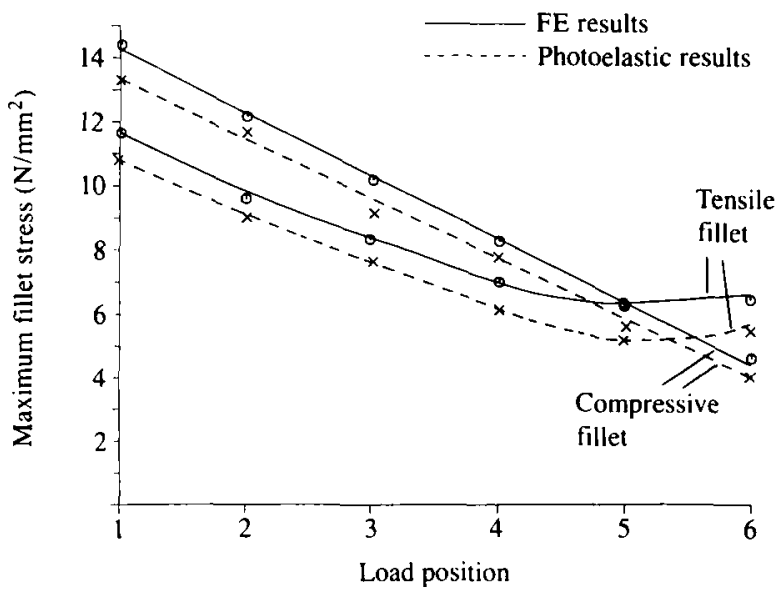

Fig. 9. Comparison of stresses evaluated using photoelastic and finite element techniques
(1) it would establish whether the finite element mesh used was able to accurately represent the behaviour of a loaded gear tooth;

(2) if trends observed in the stress distribution during the photoelastic modelling were repeated using a totally independent technique, then the results could confidently be concluded to represent the behaviour of loaded gears.

Initially, finite element analyses were carried out with the load applied normally to the tooth flank at six different positions. To reproduce the photoelastic investigation a load of $222.49 \mathrm{~N}$ was applied to the surface and the material properties of the photoelastic material specified as $2930 \mathrm{~N} / \mathrm{mm}^{2}$ for the elastic modulus and 0.4 for Poissons ratio. The finite element mesh constructed for this purpose consisted of 156 eight-noded elements giving a total of 539 nodal points.

Figure 9 gives a direct comparison between the maximum fillet stresses predicted by the mathematical model and those recorded during the photoelastic tests. As can be seen, the fillet stresses produced by the finite element analysis are slightly higher than the corresponding values produced by the photoelastic study. The difference in magnitude of the fillet stresses is not great and is consistent in both compressive and tensile fillets for each position of load application.

The maximum stresses induced in the fillet portion of the gear tooth were also investigated. The trends shown in the stresses in this gear tooth were identical to those described in the previous section and illustrated in Fig. 8.

\section{THE GEOMETRY OF INTERNAL INVOLUTE SPUR GEARS}

For an internal gear, load is transmitted between the concave side of the internal gear and the convex side of the external gear. The involute of the gear tooth profile is the same for both gear types, the internal tooth shape being equivalent to the space generated between external spur gears. In normal meshing conditions the mating spur pinion operates inside the internal gear imposing possible sources of interference that are not present between two mating external gears (14) (15).

Internal gear generation is achieved using pinion cutters. During the cutting process the centre distance between the pinion cutter and the internal gear is successively increased until the required, pre-determined value is achieved. The internal gear, the generating pinion cutter and the external gear with which the internal gear will mesh, must all cooperate with the same imaginary rack having module $m_{\mathrm{t}}$ and profile angle $\alpha_{\mathrm{t}}$.

For non-modified gears the median line of the imaginary rack is tangent to the pitch cylinder. Modified gears are generated when the median line of the rack and the tangent to the pitch cylinder are not coincident. The distance between the two lines is defined by the modification factor $s_{0}$.

Pinion cutters can be defined by the following parameters:

$\begin{array}{ll}\text { number of teeth } & Z_{\mathrm{c}} \\ \text { module } & m_{\mathrm{t}} \\ \text { pressure angle } & \alpha_{\mathrm{t}} \\ \text { addendum } & h_{\mathrm{c}}=m_{\mathrm{t}} h_{0 \mathrm{c}} \\ \text { tip rounding radius } & r_{\mathrm{r}}=m_{\mathrm{t}} r_{\mathrm{ot}}\end{array}$


The tools are non-modified and so no modification factor is required for the cutter. From these quantities the following relations can be expressed which are necessary to define the profile of the generated internal gear.

Base circle radius $r_{\mathrm{bc}}=\frac{m_{\mathrm{t}} Z_{\mathrm{c}}}{2} \cos \left(\alpha_{\mathrm{t}}\right)$ (cutter)

$$
r_{\mathrm{bg}}=\frac{m_{\mathrm{t}} Z_{\mathrm{g}}}{2} \cos \left(\alpha_{\mathrm{t}}\right) \text { (gear) }
$$

Cutter tip radius $\quad r_{\mathrm{T}_{\mathrm{c}}}=\frac{m_{\mathrm{l}} Z_{\mathrm{c}}}{2}+h_{\mathrm{c}}$

The pressure angle of the generated gear $\alpha_{\mathrm{g}}$ is obtained from

$$
\operatorname{inv}\left(\alpha_{\mathrm{g}}\right)=\operatorname{inv}\left(\alpha_{\mathrm{l}}\right)+\frac{2 s_{0}}{Z_{\mathrm{g}}-Z_{\mathrm{c}}} \tan \left(\alpha_{\mathrm{l}}\right)
$$

The radii of the generating pitch cylinders

$$
r_{\mathrm{p}_{\mathrm{g}}}=\frac{r_{\mathrm{bg}}}{\cos \left(\alpha_{\mathrm{g}}\right)} \text { and } r_{\mathrm{pc}_{\mathrm{c}}}=\frac{r_{\mathrm{bc}}}{\cos \left(\alpha_{\mathrm{t}}\right)}
$$

The centre distance, $a_{\mathrm{g}}$ between pinion and gear

$$
a_{\mathrm{g}}=\frac{m_{\mathrm{t}}}{2}\left(Z_{\mathrm{g}}-Z_{\mathrm{c}}\right) \frac{\cos \alpha_{\mathrm{t}}}{\cos \alpha_{\mathrm{g}}}
$$

The radii of the tip and root cylinders of the gear

$$
\begin{aligned}
& r_{\mathrm{T}_{\mathrm{g}}}=m_{\mathrm{t}}\left(\frac{Z_{\mathrm{g}}}{2}+s_{0}-a_{0 \mathrm{~g}}\right) \\
& r_{\mathrm{R}_{\mathrm{g}}}=m_{\mathrm{t}}\left(\frac{Z_{\mathrm{g}}}{2}+s_{\mathrm{O}}+a_{0 \mathrm{c}}\right)
\end{aligned}
$$

The tip and root cylinders of the internal gear teeth are given by equations (10) and (11), respectively, between these cylinders the tooth profile is formed by the involute and fillet curves. The equations of these curves are given in terms of a local coordinate system $(\xi, \eta)$. As shown in Fig. 10 the $\eta$ coordinate axis forms the centre line of the internal gear with the origin of the system at the centre of the gear.

For the involute curve the angle $\psi>0$ has been chosen as the generating parameter. From $\psi$ the angle $\theta$ is given by

$$
\theta=\frac{\pi-4 s_{0} \tan \left(\alpha_{\mathrm{t}}\right)}{2 Z_{\mathrm{g}}}-\operatorname{inv}\left(\alpha_{\mathrm{t}}\right)+\operatorname{inv}(\psi)
$$

From Andersson's work (16) the involute coordinates are then

$$
\begin{gathered}
\xi_{\mathrm{i}}=\frac{r_{\mathrm{b}} \sin (\theta)}{\cos (\psi)} \\
\eta_{\mathrm{i}}=\frac{r_{\mathrm{b}} \cos (\theta)}{\cos (\psi)}
\end{gathered}
$$

For the fillet curve which joins the involute curve to the tooth root cylinder, the profile equations are derived in terms of $\phi$ the angle between the line of symmetry, and a line joining the origin to the rolling point. The angle $\phi$

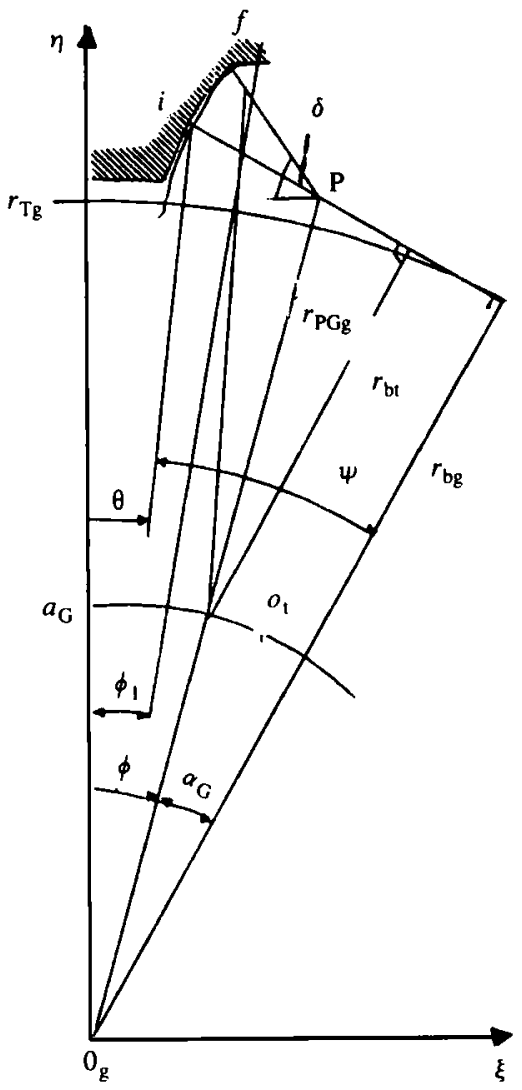

Fig. 10. Internal teeth generated by pinion cutter

can then be determined from

$$
\tan (\psi)=\phi+\alpha_{g}+\operatorname{inv}\left(\alpha_{t}\right)-\frac{\pi-4 s_{0} \tan \left(\alpha_{0}\right)}{2 Z_{g}}
$$

At the point where the fillet joins the root, the tip rounding centre of the tool intersects the line from the gear centre through the rolling point. This point is generated when $\phi=\phi_{1}$ given by

$$
\phi_{1}=\frac{Z_{\mathrm{c}}}{Z_{\mathrm{g}}}\left(\frac{\pi}{Z_{\mathrm{c}}}-\beta_{\mathrm{c}}\right)
$$

and

$$
\beta_{\mathrm{c}}=\frac{\pi}{2 Z_{\mathrm{c}}}+\operatorname{inv}\left(\alpha_{\mathrm{t}}\right)-\frac{r_{\mathrm{r}}}{r_{\mathrm{bc}}}-\operatorname{inv}\left\{\cos ^{-1}\left(\frac{r_{\mathrm{bc}}}{r_{\mathrm{T}_{\mathrm{c}}}-r_{\mathrm{r}}}\right)\right\}
$$

Fillet coordinates $\xi_{\mathrm{f}}, \eta_{\mathrm{f}}$ are then obtained from

$$
\begin{aligned}
& \xi_{\mathrm{f}}=\xi_{\mathrm{D}}-r_{\mathrm{r}} \cos \delta \\
& \eta_{\mathrm{f}}=\eta_{\mathrm{D}}+r_{\mathrm{r}} \sin \delta
\end{aligned}
$$

in which

$$
\begin{aligned}
& \xi_{\mathrm{D}}=a_{\mathrm{g}} \sin \phi+\left(r_{\mathrm{T}_{\mathrm{c}}}-r_{\mathrm{r}}\right) \sin \left(\phi-\frac{Z_{\mathrm{g}}}{Z_{\mathrm{c}}}\left(\phi-\phi_{1}\right)\right) \\
& \eta_{\mathrm{D}}=a_{\mathrm{g}} \cos \phi+\left(r_{\mathrm{T}_{\mathrm{c}}}-r_{\mathrm{r}}\right) \cos \left(\phi-\frac{Z_{\mathrm{g}}}{Z_{\mathrm{c}}}\left(\phi-\phi_{\mathrm{f}}\right)\right) \\
& \xi_{\mathrm{p}}=r_{\mathrm{p}_{\mathrm{g}}} \sin \phi \\
& \eta_{\mathrm{p}}=r_{\mathrm{p}_{\mathrm{g}}} \cos \phi
\end{aligned}
$$

JOURNAL OF STRAIN ANALYSIS VOL 26 NO 31991 (C) IMechE 1991 
and

$$
\delta=\tan ^{-1}\left(\frac{\eta_{\mathrm{D}}-\eta_{\mathrm{p}}}{\xi_{\mathrm{D}}-\xi_{\mathrm{p}}}\right)
$$

The point of intersection between involute and fillet curves occurs when $\phi=\phi_{2} \cdot \phi_{2}$ is given in terms of $\psi_{2}$ by equation (14) where $\psi_{2}$ is obtainable from

$$
\tan \psi_{2}=\frac{a_{\mathrm{g}} \sin \alpha_{\mathrm{g}}+\sqrt{ }\left\{\left(r_{\mathrm{T}_{\mathrm{c}}}-r_{\mathrm{r}}\right)^{2}-r_{\mathrm{bc}}^{2}\right\}+r_{\mathrm{r}}}{r_{\mathrm{bg}}}
$$

\subsection{Automatic mesh generation}

As for the external gear, a computer program, has been designed to automatically carry out the labour intensive task of producing a finite element mesh over the internal gear profile. From the input parameters which define both the geometry of the internal gear tooth and the resolution of the discretisation process a finite element mesh is constructed and the data defining the mesh written to a data file.

The parameters which define an internal involute gear relate to either the generated internal tooth itself or the cutting pinion used to machine it. The nine parameters used to define the tooth are:

(1) number of teeth on the internal gear $\left(Z_{\mathrm{g}}\right)$;

(2) modification factor between the generated gear and the cutting pinion $\left(s_{0}\right)$

(3) addendum factor of the gear tooth $\left(a_{0_{g}}\right)$;

(4) pressure angle of the cutting pinion $\left(\alpha_{t}\right)$;

(5) module $\left(m_{t}\right)$;

(6) addendum factor of the cutting pinion $\left(a_{0 \mathrm{c}}\right)$;

(7) number of teeth on the cutting pinion $\left(Z_{c}\right)$;

(8) tip radius factor of the cutting pinion $\left(r_{0 c}\right)$;

(9) thickness $(t)$.

The approach to generate a finite element mesh over the internal gear tooth is similar to that used for the external gear. That is thirteen key points are determined at positions on the tooth periphery (Fig. 11) and are then used in conjunction with the equations described above to generate the tooth geometry.

The curved surfaces of the tooth on the flank and in the fillet are represented by equations (13) and (17). For these portions of the mesh boundary, the values of the generating angles $\psi$ and $\phi$ for any nodal point on the flank or fillet, respectively, are required. These can also

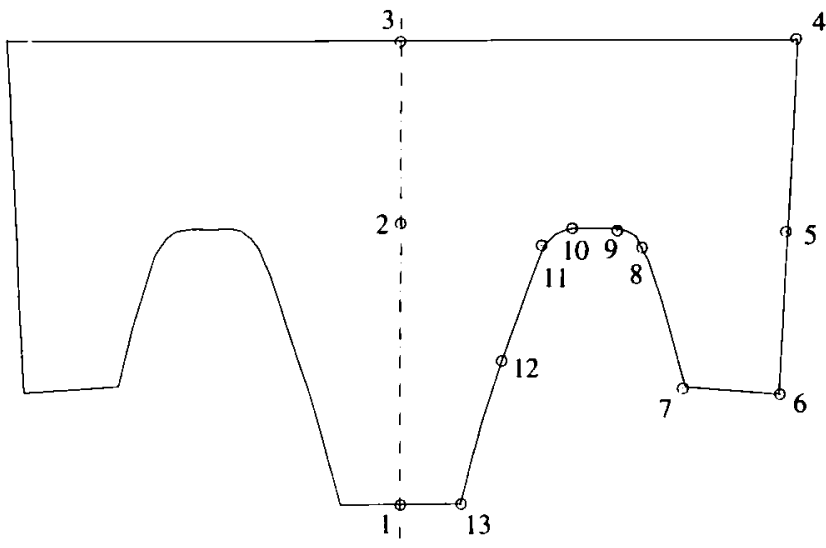

Fig. 11. Internal gear tooth definition points be obtained by linear interpolation between the generating angles which correspond to the definition points $(10)-(11)$ and (11) $-(13)$ which bound the fillet and flank portions of the tooth, respectively.

The program formulates the finite element mesh in three stages as described for the generation of meshes for external gears.

\section{INTERNAL GEAR TOOTH BENDING STRESSES}

The finite element mesh used to model the internal gear form was constructed using a total of 119 isoparametric elements linking 418 nodal points (Fig. 12). This is comparable in terms of element resolution to the meshes used in the analysis of the stresses in external gears. The location of the model boundary was also fixed according to the detailed investigation made during the work carried out on external gears.

Of the total number of 836 degrees of freedom in the discretisation of the gear tooth structure, those associated with nodal points lying on the prescribed boundary were restrained from movement.

The gear tooth represented by the finite element mesh is defined by the following parameters:

number of teeth 40 ;

modification factor $\quad 0.0$;

addendum factor $\quad 1.0$;

pressure angle of tool 20 degrees;

module $\quad 5.0 \mathrm{~mm}$;

addendum factor of the tool 1.25 ;

number of teeth on cutter $\quad 10.0$;

tip radius factor of cutter $\quad 0.1$;

As the internal gear meshes with a pinion the point of contact will traverse the working length of the gear flank. Six load points have again been chosen along the gear flank as indicated in Fig. 12. A load of $400 \mathrm{~N} / \mathrm{mm}$ was then applied perpendicular to the gear face at each of these positions in turn and the resulting model analysed.

\subsection{Fillet surface stresses}

The stresses resulting from the different loading points are plotted for the compressive and tensile fillets (corresponding to the portion of the flank labelled $\mathrm{YZ}$ in Fig. 12) in Figs. 13 and 14, respectively. Fillet surface locations indicated on the base of the graph have been obtained by projecting their positions onto a straight line placed adjacent to the tooth flank.

Compressive fillet stresses, shown in Fig. 13, form a consistent family in which, as expected, lower stress levels are experienced for lower load positions on the tooth

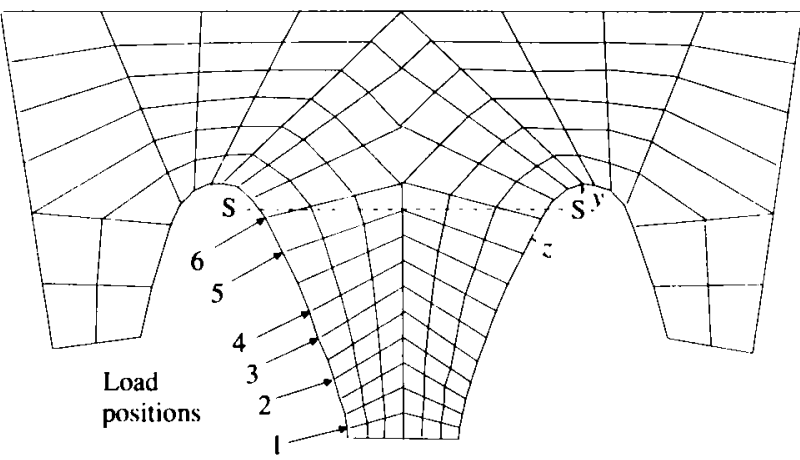

Fig. 12. Finite element mesh of the internal gear 


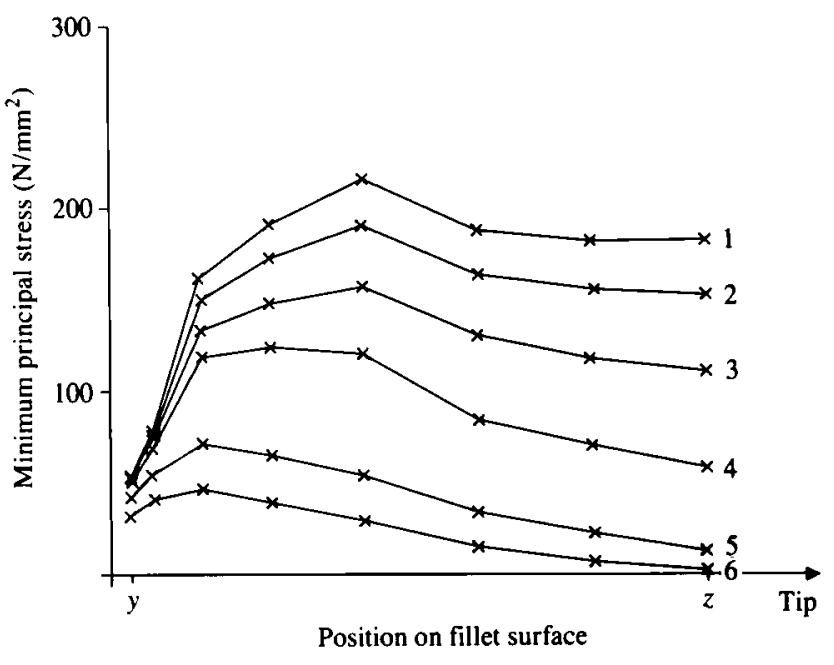

Fig. 13. Variation of minimum principal stress with load position for the compressive fillet

flank. Once again there is a distinct shift in the position on the fillet surface at which the maximum stress intensity is attained. The shift occurs in the same direction as the movement of load; as the load approaches the tooth fillet the stress concentration moves around the fillet away from the load point. Each of the features of the family of stress distributions obtained for the compressive fillet of the internal gear was consistent with those which occurred in the results for the external gear tooth.

Figure 14, which shows the tensile fillet results, forms a more complicated set of profiles. As with other tooth forms, the anomalies which cause a deviation from the consistent family of results are more apparent in the fillet on the loaded side of the tooth. Load positions $1-4$ produce the expected results, with the stress intensities reducing as the bending moment decreases. For positions 5 and 6 , however, where load is applied near to the fillet region, the predicted stresses deviate from the previously well-defined pattern. Peak stress values attained for these two load points exceed some of those associated with higher load positions and, therefore, greater bending moments. Indeed at load position 6 , which is very close to the tooth fillet, only loading very close to the other extreme, the tooth tip, produced a greater stress

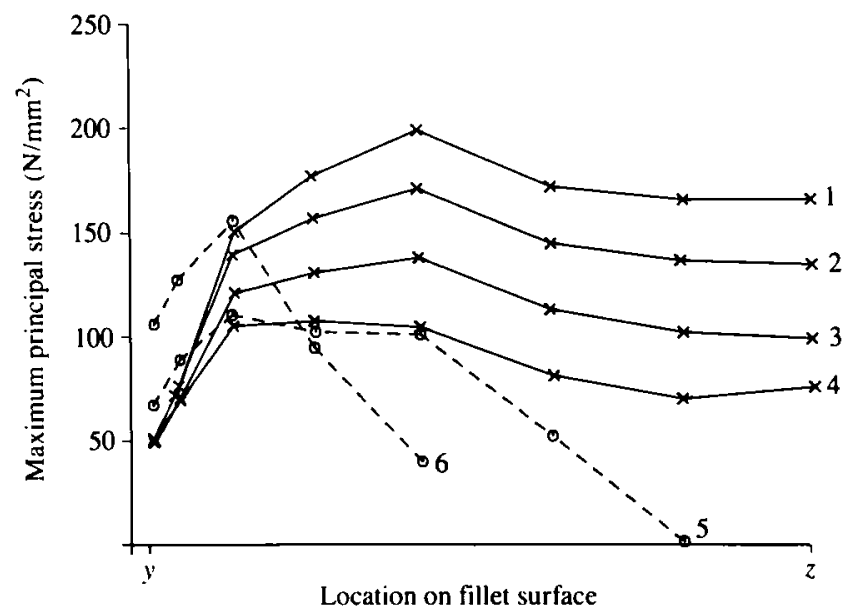

Fig. 14. Variation of maximum principal stress with load position for the tensile fillet intensity. These features were identified in the analysis of external gear tooth stresses.

The magnitude of peak compressive and tensile fillet stresses are plotted in Fig. 15. For load positions remote from the fillet, the maximum compressive fillet stress exceeds the tensile fillet value. This changes at low load positions where a crossover in the maximum fillet stress values occur. The very high tensile stress value attained at load position six is possibly due to the relatively small fillet radius on the internal tooth having a high stress concentration effect.

\subsection{Root section stresses}

Principal stresses and their Cartesian stress components are plotted across a root section in Fig. 16. The location of the root section with respect to the main tooth has been arbitrarily selected and corresponds to a section drawn perpendicular to the tooth centre line at approximately mid-depth of the fillet curve (line S-S Fig. 12).

When load is applied on the flank away from the fillet region at positions 1 and 3 the stress variation over the sections are consistent and, as expected, are of lower magnitude for the lower load positions. Principal stress intensities reach maximum values in the appropriate fillets and produce relatively low stresses over the remainder of the section. Stresses resolved into their Cartesian components over the section are also consistent for load positions 1 and 3. The graphs indicate that a shear stress concentration resides in both fillets whilst only a moderate shear intensity is produced at the centre of the tooth. The direct stress distribution $\sigma_{y}$ produces a surprising result for load position 1 (Fig. 16(a)) in that it appears to have a linear variation over the section. If this trend were to be true for each position of load then it may provide some justification for basing gear tooth bending stress formulae on cantilever beam theory. This proved to be a coincidence for this particular combination of tooth variables and was not repeated in other results obtained from other load conditions.

Stress results predicted when a load was applied at a low position on the internal tooth are illustrated in Fig. 16(c). A change in the behaviour of both principal stresses and their components was found when compared to the stresses illustrated in Figs. 16(a) and 16(b). The changes result from the contribution of the stress

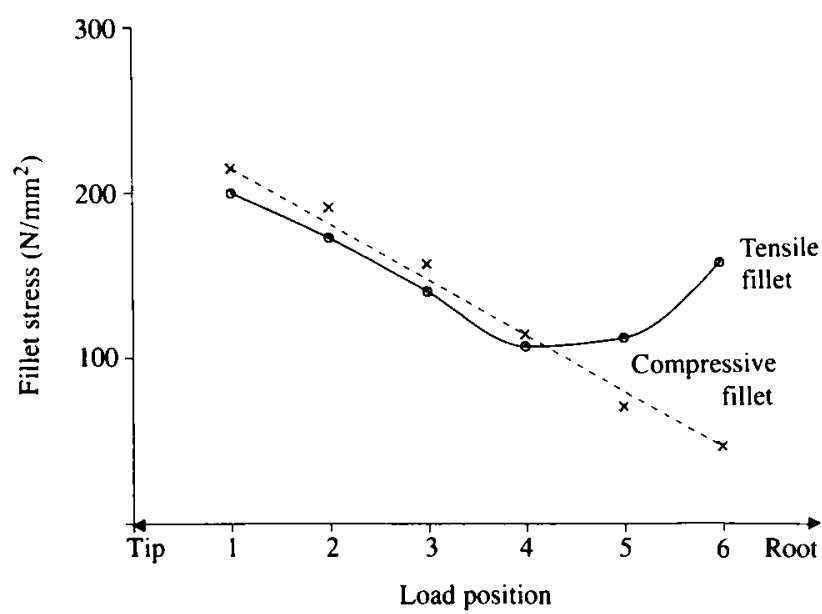

Fig. 15. Variation of maximum fillet stress with load position 


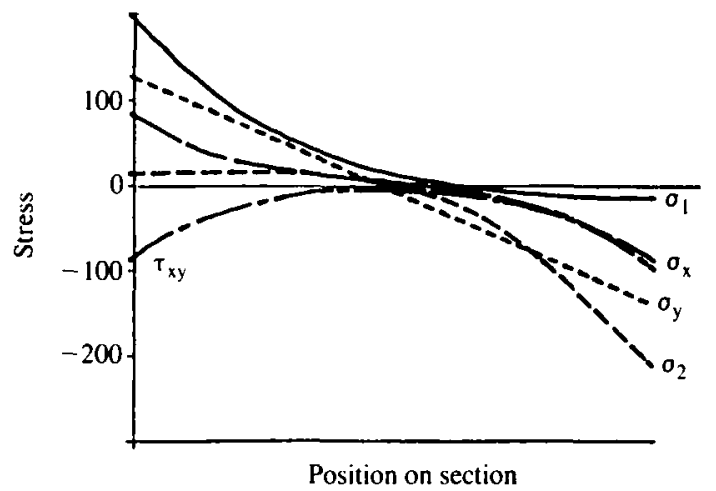

Fig. 16(a). Root section stresses for load position 1

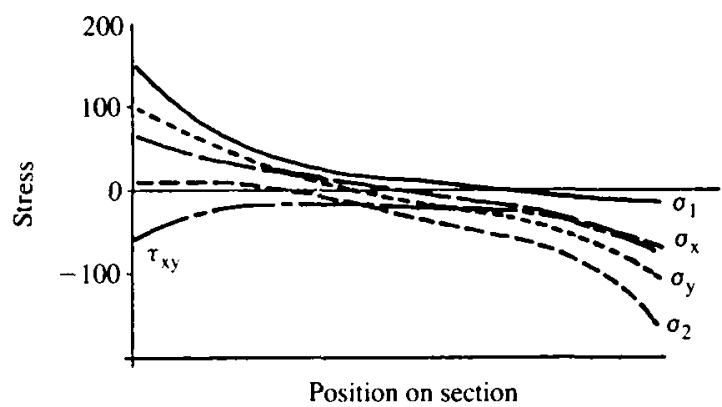

Fig. 16(b). Root section stresses for load position 3

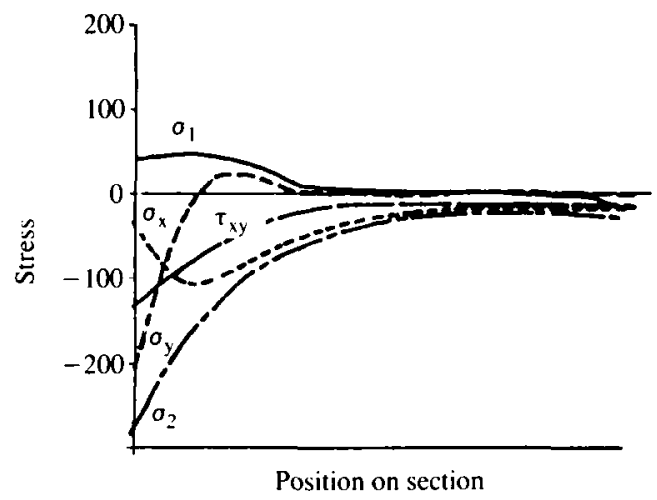

Fig. 16(c). Root section stresses for load position 6

field produced by the contact region which, for load position 6 , has developed into the fillet portion of the tooth. Contact stresses then dominate the bending stresses which result from a relatively small moment. Significant levels of stress are then only produced in the fillet on the loaded side of the tooth.

\section{CONCLUSIONS FOR SPUR GEAR BENDING STRESS}

From the observations made of results obtained by the finite element analysis of spur gear teeth there is a very close relationship between the stress distributions predicted for both the internal and the external forms of the gear. Whilst no constructive comments or conclusions can be drawn about the relative magnitude of the stresses induced by the same load in each particular form, trends in the stresses produced are similar and the same conclusions were derived from each set of results.

(1) The plot of the variation of the stress $\sigma_{y}$ across the root section of spur gear teeth shows that the behaviour of the tooth under load is not comparable with that of a cantilever beam, as has been assumed in many previous theoretical treatments.

(2) Maximum compressive fillet stresses decrease as the point of load application descends from the highest point of tooth contact to the lowest contact for the meshing cycle.

(3) Maximum tensile fillet stresses decrease as the load point descends the flank provided the load point is remote from the fillet region. When load is applied near to the fillet region an increase in the tensile fillet stresses attributed to 'proximity effects' occurs.

(4) As the point of load application descends the gear flank, the positions of maximum stress in both tensile and compressive fillets move round the fillet in the same direction as the load movement.

(5) For loads applied at positions along the flank in approximately the top two-thirds of the gear tooth the maximum compressive stress is greater than the maximum tensile stress. This trend is reversed as the load point approaches the fillet.

Comparison between tooth fillet stresses predicted by photoelastic and finite element methods were in good agreement and the accuracy of the finite element model was confirmed. Better predictions for maximum fillet stresses can be obtained by direct application of the finite element method rather than by the use of semi-empirical formulae which have known deficiencies. This can be cheaply and quickly accomplished for any proposed design since finite element software and digital computers are now commonly available to design engineers.

\section{APPENDIX \\ REFERENCES}

(1) LEWIS, W., 'Investigation of the strength of gear teeth', Proc. Engng Club, Phil., 1893, p. 16-23

(2) HEYWOOD, R. B., Tensile fillet stresses in loaded projections, Proc. Instn mech. Engrs., 1948, 159, 384.

(3) JACOBSON, M. A., Bending stresses in spur gear teeth, Proc. Instn mech. Engrs, 1955, 169, 587.

(4) DOLAN, T. J. and BROGHAMER, E. L., 'A photoelastic study of stresses in gear tooth fillets', Univ. Ill. Bull. No. 355, 1942.

(5) KELLEY, B. W. and PEDERSEN, R., 'The beam strength of modern gear tooth design', Trans. S.A.E., NY 1957.

(6) MUDD, G. C., 'A numerical means of predicting the fatigue performance of nitride-hardened gears', Int. Conf. Gearing, 1969, I. Mech. E, London, 184, 95-104.

(7) CHABERT, G., DANGTRAN, T. and MATHIS, R., 'An evaluation of stresses and deflection of spur gear teeth under strain', $J$. Engng Ind., 1974, 96, 85-93.

(8) SHOTTER, B. A., 'A new approach to gear tooth root stresses', $J$. Engng Ind., Trans. ASME, 96, Ser B nl, Feb. 1974, 11-18.

(9) ALLISON, I. M. and HEARN, E. J., 'A new look at the bending strength of gear teeth, Expl. Mech., 1980.

(10) WENNERSTROM, E., 'Stresses in external involute spur gears', Acta Polytechn. Scand. Mech. Engng. Ser. 1970, No. 53.

(11) BUCKINGHAM, E., Analytical mechanics of gears, 1949, (McGraw-Hill, London).

(12) ANDREWS, J. D. and HEARN, E. J., 'An automatic design optimization procedure to minimize fillet bending stresses in involute spur gears' Int. J. Numer. Methods Engng, 24, 1987, 975-991.

(13) RAMAMURTI, V. and GUPTA, L. S., 'Dynamic stress analysis of a spur gear', ASME paper 79-Det-38.

(14) POLDER, J. W., 'Overcut, a new theory for tip interference in internal gears', J. Mech. Engng Sci, 1969, 11, 583-591.

(15) TUPLIN, W. A., 'Tip interference in internal gears', The Engineer, 1967.

(16) ANDERSSON, S. A. E., 'On the design of internal involute spur gears', Trans. of Machine Elements Division, Lund Technical University, Sweden 1973. 